\title{
To what extent does socio-economic status still affect household access to water and sanitation services in South Africa?
}

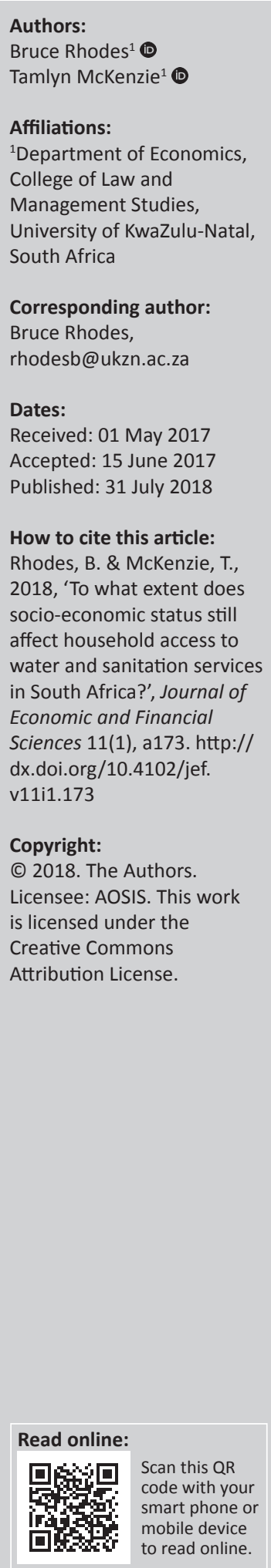

It is publically acknowledged that South Africa has recently met its millennium development goal of halving water and sanitation services (WSS) backlogs. However, significant deficits remain, especially in the case of sanitation. These shortfalls are unevenly distributed across provinces and can be tracked by socio-economic status. This article seeks to examine and identify the socio-economic factors that may affect poor WSS provision in South Africa. Using the 2014 South African General Household Survey, socio-economic indicators and access to WSS were analysed. Descriptive statistics and multivariate analysis indicate that access to WSS is largely determined by province, race and geographical location. It appears that higher quality levels of sanitation are less accessible relative to piped water access. Identifying these socio-economic factors affecting WSS provides obvious policy direction and better-targeted water infrastructural development.

\section{Introduction}

In 1994, the new democratic government faced massive regional and racial differences with regard to adequate water and sanitation services (WSS) (Department of Environmental Affairs 2012). This served as a key indicator of historical neglect and underdevelopment that significantly contributed to the high levels of countrywide absolute and relative poverty. In 2000, along with 189 other countries, South Africa adopted the eight millennium development goals (MDG) (Choffnes \& Mack 2009). Goal 7 of MDG target 10 was to 'halve by 2015 the proportion of people without sustainable access to safe drinking water and basic sanitation' (Department of Environmental Affairs 2012; Hutton \& Bartram 2008:13). For South Africa, the safe drinking water goal was achieved in 2005, but the drive for sanitation requires more time where, 'the goal of eliminating the full sanitation backlog by 2014 may seem too ambitious' (UNDP 2011:94).

From a general perspective, providing safe and reliable WSS is a huge and costly undertaking, especially in a developing country context. The World Health Organization estimates the economic costs of poor sanitation to be around $\$ 23.5$ billion for sub-Saharan Africa or 5\% of GDP (Choge \& McCornick 2010). Furthermore, it is estimated that for every $\$ 1$ spent on sanitation there is an average return of $\$ 9$ of benefits such as gains from children staying in school and general health benefits, particularly from a reduced incidence of diarrhoea (World Bank 2011 in Tissington 2011).

MDG aside, the South African government has itself spent billions in the WSS development process. Going beyond the goals, to provide full universal access by 2015, it was estimated that the government would need to spend the equivalent of US \$857 million per annum and \$1.21 billion per annum as the required investment to meet the total backlog of upgrading water supply services and sanitation facilities, respectively, including all the informal settlements in association with the housing programme (World Bank 2011). Total operating and maintenance costs were estimated to be $\$ 530$ million per annum for water supply services and $\$ 493$ million per annum for sanitation facilities (World Bank 2011). Unsurprisingly, in each case, the majority of this operation cost is required in urban areas, especially for sanitation.

Given this high cost, a greater understanding of how and where to target development is required. To improve social returns on public investments, the socio-economic characteristics of the households most in need of better WSS is required to help sharpen the focus of water policy in terms of allocating water-based resources, infrastructure provision and, ultimately, water pricing. The need for higher social returns will continue to grow as water resources in general become 
more strained. Despite the drive for universal access, policies have to be sensitive to ecological constraints, especially so in South Africa, given its uneven rainfall patterns and climatic variability (Department of Environmental Affairs 2012).

In South Africa, there is little recent work on identifying the socio-economic characteristics of households that access piped water and even less on the equivalent analysis for sanitation over the same sample. As such this research is focused on identifying those households that (1) access piped water and (2) access a flush toilet. Comparing access to piped water and flush toilets enables a relative comparison of useful progress indicators.

The section 'Background' gives a brief background of South African WSS targets, the challenges faced by the government and progress made since 1994. This section is concluded by a review of the specific relevant economics literature on socioeconomic predictors of water access and sanitation. The section 'Data and methods' details the chosen methodology of investigation and econometric specification followed by results in the section 'Results' and a concluding discussion in the section 'Discussion'.

\section{Background}

Historically, in South Africa, clean piped water and a flush toilet were associated with white privilege, with the majority of black South Africans only having access to dry toilets (Eales 2011). In 1994, South Africa faced a huge WSS backlog, and in the spirit of the Reconstruction and Development Programme and Bill of Rights, the South African government drew up the White Paper on Water Supply and Sanitation Policy (Tissington 2011). Since then, it has made a clear commitment to ensuring a free basic water supply for all by 2013 and 2014 (defined as 25 L per person per day of acceptable quality at a minimum flow of $10 \mathrm{~L}$ per minute, no more than 200 million from the home, available at least 350 days and uninterrupted for less than 48 consecutive hours per supply incident) (Okonkwo 2010; Statistics South Africa 2011). In 1995, a National Sanitation Task Team was set up to coordinate the relevant national departments in a recovery of the national sanitation backlog (Tissington 2011).

In 1997, South Africa declared basic water and sanitation a human right under the auspices of the Water Services Act (1997), consistent with the Bill of Rights (Statistics South Africa 2011), but in 2005, it was estimated that about 6 million South Africans still lacked access to basic level of service (Cullis 2005). Achieving the 2013 and 2014 targets was always going to be difficult in a country not known for its abundance of water. In addition to basic human rights and dignity issues surrounding WSS, failure to secure safe and reliable WSS can exacerbate the effects of climate change and population growth, cause excessive migration and force people to use unclean water sources, placing undue burden on health services and water collectors (typically women) and increasing the probability of deaths, especially amongst children aged under 5 years (Choge \& McCornick 2010; Dungumaro 2007; Lewin et al. 2007).

After publishing the National Sanitation Policy in 1996 (much like the 1994 Water Supply and Sanitation Policy), the 2001 White Paper on the Basic Household Sanitation was followed by a series of initiatives, including inter alia the 2003 Water Services Framework and the National Sanitation Strategy tasked with recovering the backlog of sanitation provision by 2010. In 2009, the Department of Water Affairs (DWA) passed the Free Basic Implementation Strategy that was given the mandate to guide the 169 water service authorities across the country in fulfilling national policy as laid down by the 2001 White Paper (Tissington 2011).

Much progress has been made concerning WSS access in South Africa. Households with general access to water infrastructure has risen from $61.7 \%$ in 1994 to $95.5 \%$ by 2012 and just over 8000 households are still using a bucket system for human waste (Department of Environmental Affairs 2012). Whilst some MDG targets had been met, it is still publically acknowledged that much work needs to be done. Indeed, whilst $40.7 \%$ of households (4484) had access to piped water inside their homes in 2002, this had only risen to $41.5 \%$ (5943) by 2010 and the number of households using boreholes as their main source of drinking water had risen from 146 to 180 (1.3\%) (Statistics South Africa 2011). In addition, using 2012 data, it was estimated that South Africa had improved drinking water access (and thereby quality) by $95 \%$, whereas use of improved sanitation facilities were lower at an increase of $74 \%$ (World Health Organization; UN-Water 2014).

The statistics are crucial but the human dimension of poor WSS is staggering considering the social loss of personal hygiene, disease protection and dignity (City of Cape Town 2008). The failure of service delivery was no better highlighted than in the 2011 local government elections which saw unenclosed and very undignified public toilets being built in Khayelitsha, Cape Town, and in Rammulotsi in the Moqhaka municipality in the Free State (Department of Water Affairs South Africa 2012). Between 2007 and mid-2010, it was found that over $30 \%$ of the time, service delivery protests were owing to issues of water supply or sanitation (Tissington 2011). It seems that the poorest and the most vulnerable groups have to wait the longest for any significant change (Eales 2011).

Whilst interesting, relevant and necessary, achieving MDGs is no panacea. This article is not intended to test the feasibility of WSS based on any MDG but rather to better understand the socio-economic characteristics of households that do not have access to piped water and a flush toilet. For a given population, piped water and flush toilets for all would arguably be the end point in terms of infrastructural improvement and reversing apartheid-era neglect with maintenance the only concern. Given this development gap, examining water supply and sanitation under these criteria 
would continue to inform policy and also reveal the dual progress of WSS.

There is a growing body of literature that is making stronger links to the lack of access to safe WSS having devastating effects on labour force participation, education, cooking and food provision and equity of women, especially in rural areas (Choffnes \& Mack 2009). Within the context of the developing world, including South Africa, the risk and exposure to diarrhoea, cholera, bilharzia, trachoma, intestinal worms and hookworms, especially amongst children owing to poor water provision can be deadly (Choffnes \& Mack 2009; Hoque \& Worku 2005; Okonkwo 2010).

Much of recent theoretical and empirical water poverty research over the last decade has focused on developing a water poverty index comprising of variables representing access, use, capacity, resources and environment distilled into one neat number. Unfortunately, this has not resulted in an index definition that all can agree upon (Komnenic, Ahlers $\&$ Zaag 2009). The more comprehensive water poverty indices take into account the socio-economic variables, such as income, that help to identify water impoverished areas and guide policy (Cullis 2005; Lawrence, Meigh \& Sullivan 2002; Sullivan 2002).

There is a broad agreement that household income is a powerful predictor of domestic water quality (Sullivan 2002). This directly links to poverty where female-headed households tend to be the poorest and are thereby exposed to reduced water quality and/or poor sanitation (Kimenyi \& Mbaku 1995). It is important to note that water poverty does not necessarily arise from poor access. The pipe and tap may be accessible, but the household cannot afford to get connected.

Previous research examining associated socio-economic variables on WSS in the South African context is thin. Dungumaro (2007) found that dwelling type, income source (salaries/wages or remittances), household size and to a lesser extent gender of head of household were all good predictors of domestic water quality. Dungumaro (2007) largely confirmed the findings of Sullivan (2002) in that lowincome households in poor-quality dwellings shared by many (exacerbating poverty) are far more likely to have unsafe drinking water.

StatsSA (2011) identified significant socio-economic variables using logistic regressions with safe/unsafe water access as the binary dependent variable. This analysis was conducted using data from the 2010 General Household Survey (GHS). Safe was defined by anything other than a river, dam, well or stream. All piped water and boreholes (private or communal) are classed as a safe source (Statistics South Africa 2011). With some regional variation, access to safe water is strongly associated with home ownership and access to basic services (sanitation and refuse removal), whereas it is negatively associated with having four or less rooms, a monthly expenditure of R1800 or less and the head of household being 35 years old or less. In 2010, the Western Cape had the highest access to safe water $(92.1 \%)$ and the Eastern Cape had the lowest access (45.0\%) (Statistics South Africa 2011). No regressions were reported for sanitation services.

Whilst the few aforementioned studies identified the socioeconomic variables associated with safe/unsafe water, there is even less independent research in the South African sanitation context. Kirigia and Kainyu (2000) using 1995 data gathered from a survey of nearly 4000 households in city, township, farm and rural locations gathered socio-economic data including details of toilet ownership. It was generally found that household size, location, health insurance coverage, income, age, education (formal and health education), racial group and employment status had a significant impact upon the probability of toilet ownership (Kirigia \& Kainyu 2000).

The analysis presented later in the article builds on previous work, extends and updates it. There is little literature that focuses on the socio-economic background of water-poor households and even less over the last 10 years where it is hoped that much improvement in water facilities has occurred. The said analysis compares piped and non-piped drinking water rather than the more typical safe and unsafe distinction. According to StatsSA, safe water includes piped water in the dwelling, on-site or off-site and also from a borehole source (Statistics South Africa 2011. However, boreholes are susceptible to contamination (Esterhuizen et al. 2012; Samie et al. 2011), and so for this reason the socioeconomic variables associated with households that have piped or non-piped water were identified. The non-piped water sources therefore include boreholes, dams, wells, springs, rivers and streams.

For sanitation, the basic provision for adequate sanitation refers to a ventilated pit latrine (VIP) if it is constructed and maintained properly (Statistics South Africa 2011; Tissington 2011). As part of the drive to achieve basic sanitation targets, many pit latrines have been upgraded to the ventilated version as such remains a cost-effective way of rolling out basic sanitation provision (Tissington 2011). Whilst this is certainly laudable, it is arguable to say that universal access to a waterborne conventional flush toilet connected to a bulk sewer or septic tank system is an important threshold of development in terms of dignity and disease protection. Such a sanitation system requires 6-13 L of water per flush and needs a reliable uninterrupted water supply (Tissington 2011). For this reason, the abovementioned analysis identifies the socio-economic characteristics of households that have flush or non-flush toilets.

\section{Data and methods}

The data were drawn from the 2014 GHS. The GHS is a nationally representative cross-sectional survey that has been conducted by Statistics South Africa (Stats SA) annually since 2002. The aim of the GHS is to determine the level of 
development in South Africa. The survey questions are designed to collect information on service delivery and living conditions and cover a range of broad areas such as education, health, labour market participation and household access to services and facilities (Statistics South Africa 2014). The GHS 2014 aimed to survey a representative sample of the population by using a two-stage stratified sampling design, whereby the first stage of stratification was by province and the second stage was by urban and non-urban location within each province. The response rate was $93.7 \%$ and a total of 25361 households were successfully interviewed. The target population consisted of all private households in South Africa and is therefore only representative of non-institutionalised and non-military persons or households (Statistics South Africa 2014). All members of the households who were present at the time of the interview were asked to provide individual-level data, but only one person was asked for household-level information (typically the person identified as the household decision maker or household head).

There are also a number of questions pertaining to water access, quality and municipal service provision as well as sanitation. This study selected access to piped water as the variable describing the highest provision standard asked in the GHS. If South Africa's goal is to go beyond the MDGs and provide universal coverage, examining piped water access to households is arguably a key objective consistent with that goal. With regard to sanitation, the highest level of access is arguably access to a flush toilet. The GHS enquires about the type of toilet facility used by each household and the location of the toilet. Detailed responses regarding access to both piped water and a flush toilet then allows an investigation into how different socio-economic variables may affect such access. It is worth noting that this study, whilst examining how socio-economic variables relate to WSS access per se, also uniquely investigates water supply and sanitation separately using the same sample. This allows us to see if both are equally related to socioeconomic status.

There are a range of survey questions regarding the socioeconomic status of the household. These included questions regarding a household's geographical location (urban/rural and province), dwelling type (informal or formal), household size (number of people living in the dwelling) and access to electricity as well as information on the household head which includes educational attainment, gender and race. The choice of these variables is based on previous findings from the literature and a priori assessments. A priori, households in rural locations are expected to have less provision owing to the lack of public service infrastructure as would the more rural provinces. Provincial variation is demonstrated using GIS maps.

The type of dwelling structure captured by the GHS and the number of people living there may significantly be related to WSS provision. Along with electrical supply or lack thereof, these are all typical variables that indicate higher levels of poverty which may also be consistent with a lack of WSS. Lower levels of education are often associated with lower income earning ability and chances of employment and could be strongly linked with lower WSS. The literature has also found that female-headed households are more vulnerable to a lack of WSS and was therefore included in the study as was race given South Africa's history of underdevelopment for certain groups and communities.

In addition to these, there is information pertaining to household income and asset ownership; however, these were not used in the analysis given that the variables for race, gender and geographical location of the household serve as a sufficient proxy for socio-economic status. All socio-economic variables described above were explored using descriptive statistics. Those found to be significant were used to specify the regression. These results are presented in the next section.

The theoretical framework for the study stems from the notion that the provision of piped water and flush toilet access represent a much higher form of WSS development, reversing years of underdevelopment for certain groups and communities. Whilst costly in terms of public investment expenditure, requiring ongoing maintenance, this is ultimately a long run policy target. This was felt to be the most interesting research question, especially as both sanitation and water supply are examined separately in the same sample. As such, this framework requires that the dependent variables are built on a strict 'provision or no provision' principle of piped water and flush toilet access.

\section{Results \\ Descriptive statistics}

The question in the GHS pertaining to piped water asks for households to identify their main source of drinking water. Responses include piped water inside the dwelling, in the yard, in a neighbour's tap, in a communal or public tap, in boreholes, in rain water tank, in flowing or stagnant water amongst others. For the purpose of this analysis, a variable representing access to piped water was created. The variable is binary and equal to one if a household was identified as having access to piped water inside their dwelling, in their yard, their neighbour's tap or a communal/public tap and is equal to zero for all other water sources.

In addition, a variable representing household access to a flushing toilet was created such that it equals one if a household has a flush toilet connected to a public sewerage system or septic tank and zero if a household uses a chemical toilet, pit latrine, bucket toilet or no toilet. In South Africa, $90 \%$ of households have access to piped water whilst twothirds have access to flush toilets. ${ }^{1}$ With regard to water services, almost three-quarters of the total population have a

1.Significant at the $5 \%$ level, with respect to the categories for no piped water and no flush toilet, respectively. 
tap water source either in their dwelling or in their yard whilst just less than $20 \%$ share a piped water source (Figure 1).

Of all the households with access to piped water, just over two-thirds have access to a flush toilet (Table 1). This is indicative of the need to address access to sanitation more thoroughly as it appears that piped water access has improved over time whilst a third of South African households are still without proper sanitation.

Figure 2 indicates the ease of access and the extent to which households share sanitation amenities with other households. Results show that just under $80 \%$ of households have their own toilet facility whilst just over $20 \%$ share a facility with other households.

More than two-thirds of these households with access to flush toilets have a toilet inside their dwelling, whilst just under a third of the households have a facility outside the dwelling but within their yard (Figure 3). A very small

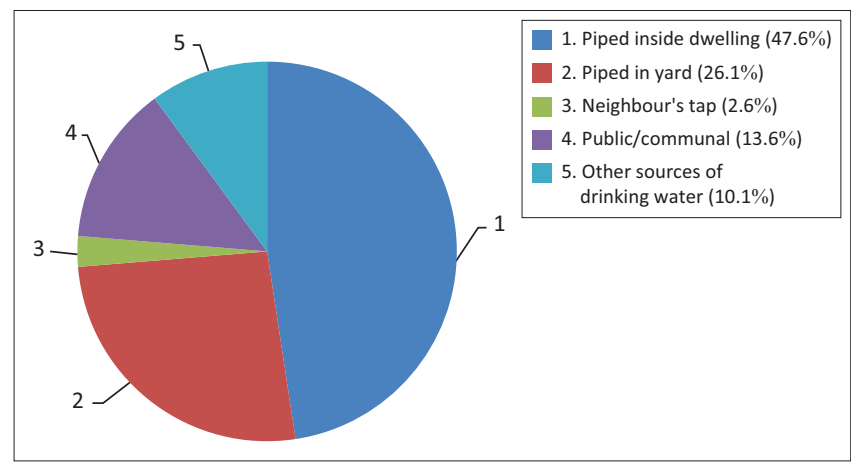

Note: Data have been weighted to be nationally representative.

FIGURE 1: Main source of drinking water for households in South Africa.

TABLE 1: Cross tabulation showing access to both piped water and flush toilet.

\begin{tabular}{llllll}
\hline Toilet type & \multicolumn{2}{c}{ Piped water } & & \multicolumn{2}{c}{ No piped water } \\
\cline { 2 - 3 } \cline { 5 - 6 } & \multicolumn{1}{c}{$n$} & $\mathbf{\%}$ & & $\boldsymbol{n}$ & $\mathbf{\%}$ \\
\hline No flush toilet & 28.3 & 0.4 & & 86.4 & 0.8 \\
Flush toilet & $71.7^{* *}$ & 0.4 & & $13.6^{* *}$ & 0.8 \\
\hline Total & $\mathbf{1 0 0 . 0}$ & & & $\mathbf{1 0 0 . 0}$ & \\
\hline
\end{tabular}

Notes: Data have been weighted to be nationally representative. Standard errors are in parentheses. **Significantly different at the $5 \%$ level compared to the 'no piped water'. percentage of households have been identified as having to access such a facility outside of their own yard (1.9\%).

A number of socio-economic status indicators in relation to household access to either piped water or a flushing toilet were analysed (Table 2). As expected, households who live in formal housing (brick house, flat, cluster home, garden cottage) are significantly more likely to have access to both piped water and proper sanitation facilities. However, the distribution of sanitation facilities has been less inclusive as compared to piped water. Only $72.6 \%$ of households classified as living in formal housing access a flushing toilet, whereas

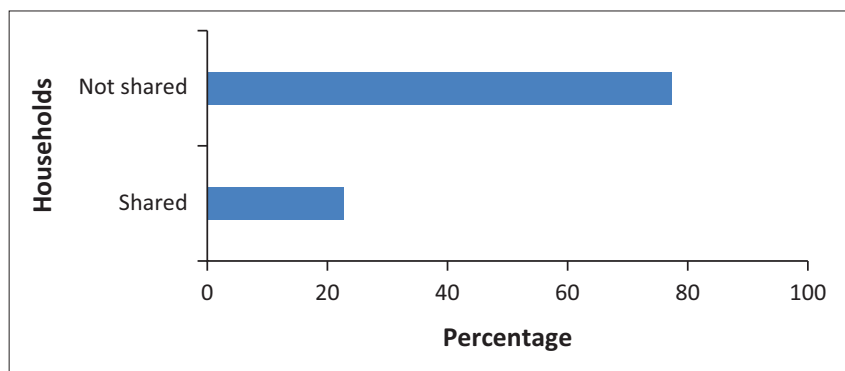

Note: Data have been weighted to be nationally representative.

FIGURE 2: Households with access to flush shared versus non-shared toilets.

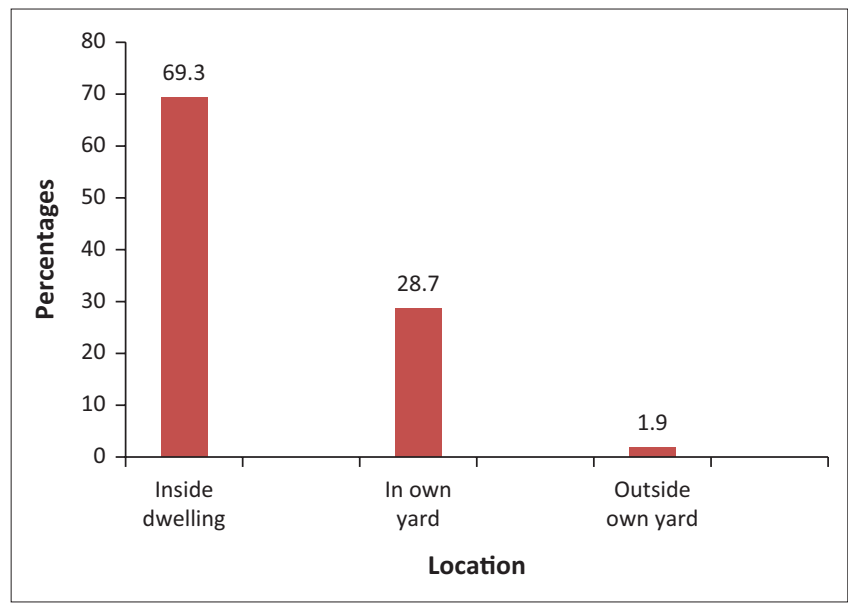

Note: Data have been weighted to be nationally representative.

FIGURE 3: Households with access to flush toilets by location

TABLE 2: Household socio-economic indicators.

\begin{tabular}{|c|c|c|c|c|c|c|c|c|c|c|}
\hline \multirow{2}{*}{$\begin{array}{l}\text { Socio-economic } \\
\text { variable }\end{array}$} & \multicolumn{2}{|c|}{ Piped } & \multicolumn{2}{|c|}{ Not piped } & \multirow[t]{2}{*}{ Total } & \multicolumn{2}{|c|}{ Flush } & \multicolumn{2}{|c|}{ No flush } & \multirow[t]{2}{*}{ Total } \\
\hline & $n$ & $\%$ & $n$ & $\%$ & & $n$ & $\%$ & $n$ & $\%$ & \\
\hline Formal housing & $91.9 * *$ & 0.2 & 8.1 & 0.2 & 100 & $72.6^{* *}$ & 0.4 & 27.4 & 0.4 & 100 \\
\hline Informal housing & $81.2^{* *}$ & 0.7 & 18.8 & 0.7 & 100 & $35.0 * *$ & 1.0 & 65.0 & 1.0 & 100 \\
\hline Urban area & $98.4 * *$ & 0.1 & 1.6 & 0.1 & 100 & $89.1^{* *}$ & 0.3 & 10.9 & 0.3 & 100 \\
\hline Rural area & $71.4 * *$ & 0.5 & 28.6 & 0.5 & 100 & $12.5^{* *}$ & 0.5 & 87.5 & 0.5 & 100 \\
\hline African & $87.9 * *$ & 0.3 & 12.1 & 0.3 & 100 & $57.1^{* *}$ & 0.5 & 42.9 & 0.5 & 100 \\
\hline Mixed race & $98.6 * *$ & 0.3 & 1.4 & 0.3 & 100 & $96.3 * *$ & 0.5 & 3.7 & 0.5 & 100 \\
\hline Indian & $99.3 * *$ & 0.3 & 0.7 & 0.3 & 100 & $99.2 * *$ & 0.3 & 0.8 & 0.3 & 100 \\
\hline White & $96.3^{* *}$ & 0.4 & 3.7 & 0.4 & 100 & $99.9 * *$ & 0.1 & 0.1 & 0.1 & 100 \\
\hline Household head is male & $91.3^{* *}$ & 0.3 & 8.7 & 0.3 & 100 & $71.6 * *$ & 0.5 & 28.4 & 0.5 & 100 \\
\hline Household head is female & $87.8^{* *}$ & 0.3 & 12.2 & 0.3 & 100 & $57.8^{* *}$ & 0.6 & 42.2 & 0.6 & 100 \\
\hline Connected to electricity mains & $91.5^{* *}$ & 0.2 & 8.5 & 0.2 & 100 & $69.5^{* *}$ & 0.4 & 30.5 & 0.4 & 100 \\
\hline Not connected to electricity mains & $91.7^{* *}$ & 1.1 & 8.3 & 1.1 & 100 & $75.1^{* *}$ & 1.8 & 24.9 & 1.8 & 100 \\
\hline
\end{tabular}

Notes: Data have been weighted to be nationally representative. Standard errors are in parentheses. **Significantly different at the $5 \%$ level compared to the 'not piped' or 'no flush' category, respectively. 


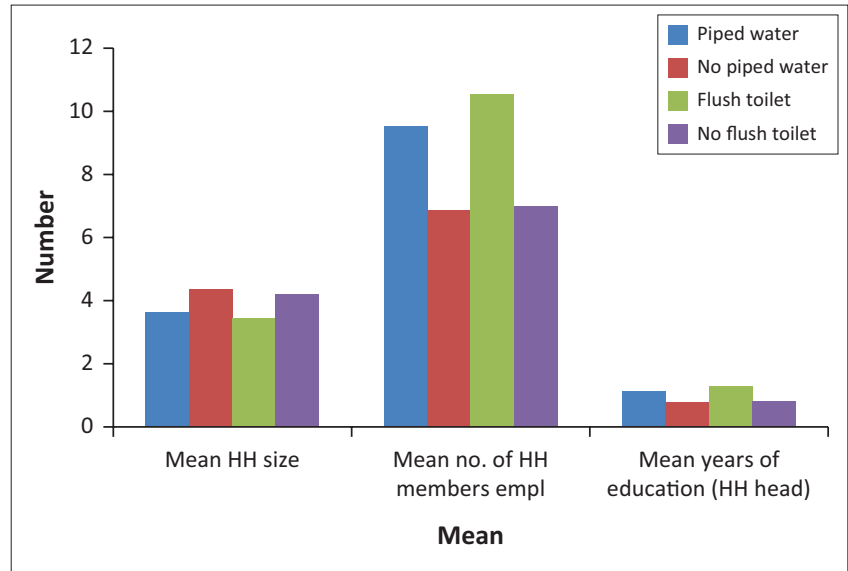

Note: Data have been weighted to be nationally representative.

FIGURE 4: Access to piped water or flush toilets by education, employment status and household size.

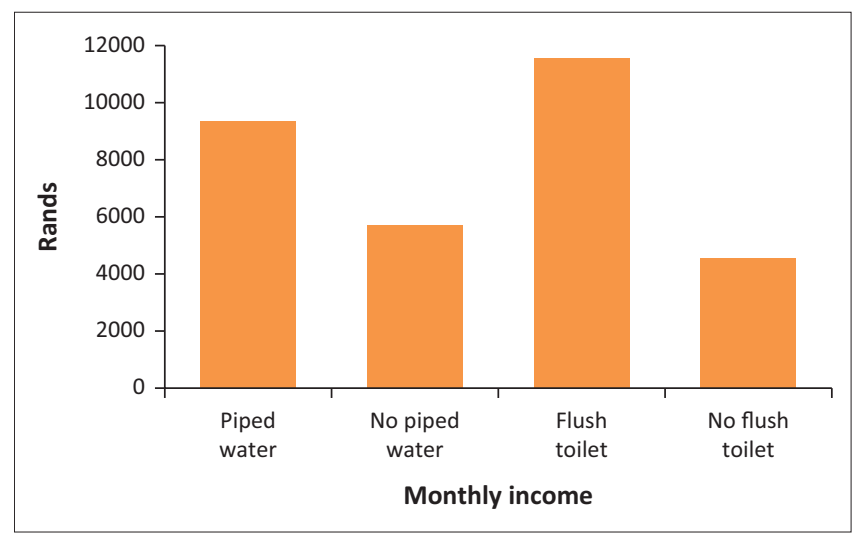

Note: Data have been weighted to be nationally representative.

FIGURE 5: Average monthly household income (incl. grants).

close to $92 \%$ access piped water. Similarly, living in an urban area significantly increases the chances of households having proper sanitation and piped water.

It is important to note that for the African subset of the population, ${ }^{2}$ access to piped water is comparable within 10 and 11 percentage points to other race groups but that gap increases to some 40 points when comparing flush sanitation facilities with Africans largely facing the lack of service provision. Similarly, just over half $(57.8 \%)$ of female-headed households compared to nearly three-quarters $(71.6 \%)$ of male-headed households have flushing toilets. Thus, race and gender of the household head serve as good proxies for socio-economic status.

Geographical differences of piped water against a flush toilet access are shown using two maps. Figure 4 shows only two provinces (Limpopo and the Eastern Cape) with $50 \%$ or less of households having piped water on the property. The Free State, Gauteng and the Western Cape are all $90 \%$ or higher.

This is now contrasted with access to flush toilet on the property in Figure 5.

2.As determined by the race identified by the household head

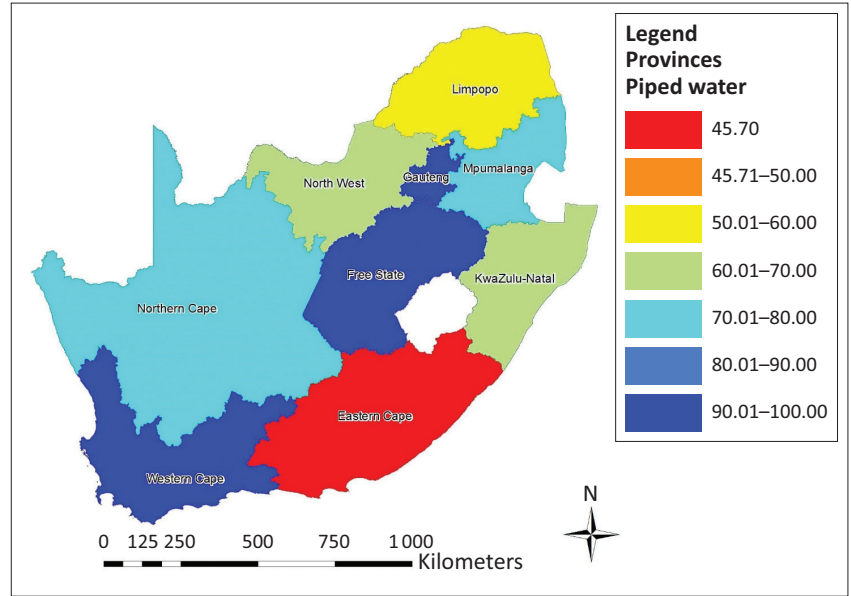

Note: Data have been weighted to be nationally representative.

FIGURE 6: Geographic distribution of households with piped water on the property.

Only the Western Cape and Gauteng maintain their 90\% or more status. Comparing the two maps, it can be clearly seen that all the other provinces drop considerably in how many households have access to a flush toilet on the property. This is consistent with Table 4 in that the households with the poorest access are the more rural provinces (notably Limpopo, the Eastern Cape and Mpumalanga). Exactly the same comparative results are found for piped water and flush toilets on or off the property.

In addition to the above, other socio-economic variables were examined. Those households with piped water tend to be smaller as larger households are typically associated with higher levels of poverty (Dungumaro 2007; Klasen \& Woolard 2000; Meth \& Dias 2004). In addition, there is a higher incidence of piped water and flush toilet access as educational years rise and as the number of employed household members increases (Figure 6). Whilst this is largely to be expected, the more interesting result is that the gaps between no flush compared to flush is larger than the corresponding gap for piped water. This potentially signals that household socio-economic status is more important in the case of flush toilet access.

These descriptive results therefore indicate that sanitation services are still lacking in comparison to piped water provision. It is clear that Africans, female-headed households and those in rural areas are mostly affected by this lack of service provision. This article will hence examine these relationships more closely by estimating a probit model to determine the extent to which socio-economic indicators can predict access to these services. Whilst it is clear that the main concern is sanitation, this article will conduct a similar analysis for both piped water and sanitation to enable comparison.

\section{Multivariate analysis}

The multivariate analysis aims to determine whether certain socio-economic indicators affect household access to piped 
water and to a flushing toilet. In both cases, as the dependent variable is binary, a probit model was used:

$Y=\beta^{\prime} X+\varepsilon$

\section{Access to piped water}

In this case, $Y$ represents a dummy variable for piped water (as mentioned above) and $\mathrm{X}$ is a vector of household-level socio-economic indicators which includes dwelling type, household size, gender, race and educational attainment of the household head, the number of household members employed, electricity connection and geographical (urban/ rural) location. Given that $71.7 \%$ of households with piped water were identified as having a flushing toilet (Table 1), the dummy variable for flush toilet was used as an additional explanatory variable.

The probit model (Eqn 1) was estimated three times, varying the explanatory variables each time so as to ensure the robustness of the results. In addition, we expect that access to piped water is a likely predictor of sanitation given that sanitation services may require piped water infrastructure; thus, these two variables may actually be collinear. The first probit (I) simply estimates the probability of accessing piped water if a household has a flush toilet. The second (II) includes the additional household-level indicators mentioned above and the third (III) excludes the variable for flush toilets.

The marginal effects of the probit estimations are presented in Table 3. Most of the variables have the expected signs and significance; however, in most cases, the marginal effects are negligible. In the first estimation (I), having a flush toilet only increases the probability of having piped water by $23 \%$; however, upon the inclusion of the additional household-level explanatory variables, this effect is reduced to $5 \%$. The most notable socio-economic driver of access to piped water is location in an urban area, raising the likelihood of access by $15 \%$. The coefficients in the second and third model estimations are very similar; however, the removal of the variable for flush toilets increases the size of the coefficient on the urban dummy variable to $22 \%$.

\section{Access to a flushing toilet}

With reference to the same equation 1 , the equivalent probit analysis was conducted for flush toilets. The dependent variable is now equal to one if a household has a flush toilet (connected to the public sewerage system or to a septic tank). The explanatory variables are identical to those included in the piped water analysis, the only exception being that the piped water dummy variable is incorporated into the analysis of access to flush toilets.

Once again the marginal effects of the probit estimations are presented in Table 3. In the first estimation (I), the probability of accessing a flush toilet increases by $62 \%$ if a household has piped water. This suggests that households with piped water typically have the infrastructure required to have a flushing toilet. Upon inclusion of the other household-level variables (II), the coefficient on piped water falls to $14 \%$ but still remains a significantly positive determinant of household access to flush toilets. The explanatory variables all have the expected signs and significance. The most prominent factors appear to be whether a household is based in an urban area or is considered to dwell in formal housing as this raises the likelihood of accessing flush toilet sanitation by over $75 \%$ and $47 \%$, respectively. Model (III) shows very similar results.

Household income (including government grants) was not included in the regressions owing to its insignificance in all models; however, the differences in income between access and no access are wider for flush toilet than piped water (Figure 7). This merely confirms that a lack of access to flush toilets affects the poorest in the country more.

Results suggest that poverty issues (informal households located in rural areas) drive access to flush toilets more so than piped water. The 2014 GHS data show that 38\% of households in rural areas are headed by Africans. Given that Africans appear to be the worst affected population group in terms of flush toilet access, the probit model (III) was reestimated for African households only (Table 4). The size and significance of the coefficients in the case of both the piped water and flush toilet do not change specifically demonstrating that the results in Table 5 are essentially driven by African households.

TABLE 3: Household socio-economic drivers of access to piped water and flushing toilet.

\begin{tabular}{|c|c|c|c|c|c|c|}
\hline \multirow[t]{2}{*}{ Socio-economic variable } & \multicolumn{3}{|c|}{ Piped water } & \multicolumn{3}{|c|}{ Flush toilets } \\
\hline & 1 & II & III & 1 & II & III \\
\hline Flush toilet & $0.16 * * *(0.00)$ & $0.04 * * *(0.01)$ & - & - & - & - \\
\hline Piped water & - & - & - & $0.62 * * *(0.01)$ & $0.14 * * *(0.03)$ & - \\
\hline Household size & - & $-0.00(0.00)$ & $-0.00 * *(0.00)$ & - & $-0.02 * * *(0.00)$ & $-0.02 * * *(0.00)$ \\
\hline $\begin{array}{l}\text { Number of household } \\
\text { members employed }\end{array}$ & - & $0.00(0.00)$ & $0.00 * *(0.00)$ & - & $0.08 * * *(0.01)$ & $0.08 * * *(0.01)$ \\
\hline Connected to electricity mains & - & $0.03 * * *(0.01)$ & $0.03 * * *(0.01)$ & - & $-0.05(0.03)$ & $-0.04(0.03)$ \\
\hline Urban & - & $0.17 * * *(0.01)$ & $0.24 * * *(0.01)$ & - & $0.75 * * *(0.01)$ & $0.77 * * *(0.01)$ \\
\hline Male & - & $-0.01 * *(0.00)$ & $-0.00(0.00)$ & - & $0.05 * * *(0.01)$ & $0.05 * * *(0.01)$ \\
\hline $\begin{array}{l}\text { Educational attainment of } \\
\text { household head (years) }\end{array}$ & - & $-0.00(0.00)$ & $0.00(0.00)$ & - & $0.03 * * *(0.00)$ & $0.03 * * *(0.00)$ \\
\hline Formal housing & - & $0.02 * * *(0.00)$ & $0.03 * * *(0.00)$ & - & $0.47 * * *(0.02)$ & $0.48^{* * *}(0.02)$ \\
\hline
\end{tabular}

Notes: Data have been weighted to be nationally representative. The marginal effects of the probit estimations are presented. Standard errors are in parentheses. Figures marked with $* * *$ are significant at the $1 \%$ level and $* *$ at the $5 \%$ level. 
TABLE 4: African household socio-economic drivers of access to piped water and flushing toilet.

\begin{tabular}{llllll}
\hline Variable & \multicolumn{2}{c}{ Piped water } & & \multicolumn{2}{c}{ Flushing toilet } \\
\cline { 2 - 3 } & \multicolumn{1}{c}{$\boldsymbol{n}$} & $\mathbf{\%}$ & & $\boldsymbol{n}$ & $\mathbf{\%}$ \\
\hline Household size & $-0.00^{* * *}$ & 0.00 & & $-0.02^{* * *}$ & 0.00 \\
Number of household members employed & $0.00^{* *}$ & 0.00 & & $0.06^{* * *}$ & 0.01 \\
Connected to electricity mains & $0.04^{* * *}$ & 0.01 & & -0.05 & 0.03 \\
Urban & $0.24^{* * *}$ & 0.01 & & $0.75^{* * *}$ & 0.01 \\
Male & -0.00 & 0.00 & & $0.03^{*}$ & 0.01 \\
Educational attainment of household & 0.00 & 0.00 & & $0.02^{* * *}$ & 0.00 \\
head (years) & & & & \\
Formal housing & $0.04^{* * *}$ & 0.00 & & $0.42^{* * *}$ & 0.02 \\
\hline
\end{tabular}

Notes: Data have been weighted to be nationally representative. The sample consists of African households only. The marginal effects of the probit estimations are presented. Standard errors are in parentheses. Figures marked with *** are significant at the $1 \%$ level,

** at the $5 \%$ level and * at the $10 \%$ level.

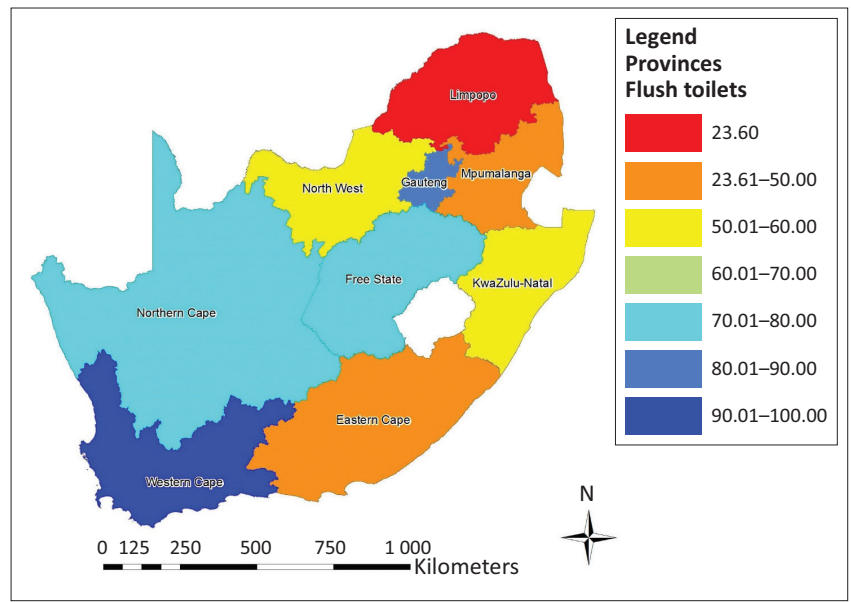

Note: Data have been weighted to be nationally representative.

FIGURE 7: Geographic distribution of households with flush toilets on the property.

\section{Discussion}

Being able to access piped drinking water and a flushing toilet is taken for granted by many. In reality, this is a luxury which many households in South Africa do not experience even after more than 20 years of democracy in Africa's largest economy. Inadequate provision of WSS is at best undignified but is potentially costly in terms of lost productivity and a health sector burden. Whilst, of course, there has been considerable progress since 1994 in achieving WSS development, consistent with previous studies, results show that progress in the domain of piped drinking water is more advanced than sanitation. As such the socio-economic variables examined here are not significant predicators of household access to piped water, whereas access to flush sanitation still appears to depend on household socioeconomic status.

Relative to piped water access, having access to a flush toilet is more dependent upon many of the socio-economic variables, as they act as poverty signals, including household size, the number of people employed in the household, connection to the electricity mains, geographical location (urban/rural), gender of the household head, educational attainment of the household head and dwelling type. A plausible explanation could be that piped water relative to flush sanitation has been largely addressed as a supply-side issue, with government expanding infrastructure to accommodate households countrywide. However, the same practice does not seem to have been applied to flush sanitation services, indicating that poorer households are significantly worse off. This could be indicative of a lack of infrastructure and service delivery in poor rural areas. Such a premise is supported by the National Planning Commission which identifies that the rural municipalities have little of the technical expertise to manage the whole supply chain of WSS projects from source to tap. Such infrastructure is a prerequisite for flush toilets which will also require additional technical support over the more basic VIP latrines.

An important aspect of water provision and motivations for improvement is health. The social health dimension of better access to quality drinking water and sanitation facilities was not enabled by the data. The only waterborne disease that is reported on in the GHS is that of very recent diarrhoea problems. The sample reporting these issues is too small to make useful inferences with regard to piped water or flush toilet ownership. This remains an interesting area for future research as adequate volumes of water and sanitation facilities are needed to support a basic level of hygiene. Increasing the quality of water access and sanitation is arguably a necessary condition for associated incremental health improvements although perhaps not sufficient. Health education may be needed to ensure appropriate behavioural changes.

Identifying and understanding the importance of the different household socio-economic characteristics remains an important part of WSS-based policy design. Despite progress, the calls for service delivery in WSS continue to get louder as expectations grow and the disparity of provision by geography, race group or otherwise widens. This article serves to highlight those important socioeconomic factors that identify water impoverished households, especially in the domain of sanitation. Policymakers would be well advised to focus attention in this area and ensure that the required level of technical ability is in place in areas of WSS scarcity. Whilst this is beyond the scope of this article, it is acknowledged that providing universal WSS has to be achieved within the limits of environmental capacities. Flush toilets are waterintensive and alternative technologies may be more appropriate as environmental constraints get tighter.

\section{Acknowledgements}

The authors wish to thank Warren Botes for his invaluable assistance in creating the GIS maps. The authors would like to thank ERSA for their input and comments in earlier drafts.

\section{Competing interests}

The authors declare that they have no financial or personal relationships which may have inappropriately influenced them in writing this article. 


\section{Authors' contributions}

Both authors conceptualised the article and designed the research questions. B.R. wrote the literature review and the main results section. T.M. ran the regressions and generated the charts and tables. Both authors wrote the discussion and concluding sections

\section{References}

Choffnes, E.R. \& Mack, A., 2009, Global issues in water, sanitation, and health National Academies Press, Washington, DC. https://doi.org/10.17226/12658

Choge, C. \& McCornick, P., 2010, Policy brief. Duke Nicholas Institute Policy Brief, Duke Nicholas Institute, Durham, North Carolina, United States.

City of Cape Town, 2008, City of Cape Town water and sanitation service standard preliminary draft 2, Water Services Report, Water and Sanitation Department, Cape Town, South Africa.

Cullis, J., 2005, Water poverty mapping: Development and introduction using a case study at the local municipal scale for the Eastern Cape, Report WRC TT 250/05. Water Research Commission, Gezina, South Africa.

Department of Environmental Affairs, 2012, Environmental sustainability indicators: Technical report, Department of Environmental Affairs, Pretoria, South Africa.

Department of Water Affairs South Africa, 2012, Report on the status of sanitation services in South Africa, Department of Water Affairs, Pretoria, South Africa.

Dungumaro, E.W., 2007, 'Socioeconomic differentials and availability of domestic water in South Africa', Physics and Chemistry of the Earth 32(15-18), 1141-1147. https://doi.org/10.1016/j.pce.2007.07.006

Eales, K., 2011, 'Transforming water management in South Africa: Designing and implementing a new policy framework', in B. Schreiner \& R. Hassan (eds.), Transforming water management in South Africa, pp. 73-96, Springer, Dordrecht, Transforming water management in South Africa, pp. 73-96,
Netherlands. https://doi.org/10.1007/978-90-481-9367-7 4

Esterhuizen, L., Fossey, A. \& Lues, J.F.R., 2012, 'Dairy farm borehole water quality in the greater Mangaung region of the Free State Province, South Africa', Water SA 8(5), 803-806. https://doi.org/10.4314/wsa.v37i4.18

Hoque, A.K. \& Worku, Z., 2005, 'The cholera epidemic of 2000/2001 in Kwazulu-Natal: Implications for health promotion and education', Health SA Gesondheid 10(4) a208. https://doi.org/10.4102/hsag.v10i4.208

Hutton, G. \& Bartram, J., 2008, 'Global costs of attaining the millennium development goal for water supply and sanitation', Bulletin of the World Health Organization 86(1), 13-19. https://doi.org/10.2471/BLT.07.046045

Kimenyi, M.S. \& Mbaku, J.M., 1995, 'Female headship, feminization of poverty and welfare', Southern Economic Journal 62(1), 44-52. https://doi.org/10.2307/1061374
Kirigia, J.M. \& Kainyu, L., 2000, 'Predictors of toilet ownership in South Africa', East African Medical Journal 77(12), 667-672, viewed 10 June 2015, from http://cat. inist.fr/?aModele=afficheN\&cpsidt=1031874

Klasen, S. \& Woolard, I., 2000, Surviving unemployment without state support: Unemployment and household formation in South Africa, IZA Discussion Paper Series, No. 237, Institute of Labor Economics, Bonn, Germany.

Komnenic, V., Ahlers, R. \& van der Zaag, P., 2009, 'Assessing the usefulness of the water poverty index by applying it to a special case: Can one be water poor with high levels of access?', Physics and Chemistry of the Earth 34(4-5), 219-224. https://doi.org/10.1016/j.pce.2008.03.005

Lawrence, P., Meigh, J. \& Sullivan, C., 2002, 'The water poverty index: An international comparison', Keele Economics Research Papers 19(October), 17. https://doi. org/10.1111/1477-8947.00054

Lewin, S., Norman, R., Nannan, N., Bradshaw, D. \& Thomas, E., 2007, 'Estimating the burden of disease attributable to unsafe water and lack of sanitation and hygiene in South Africa in 2000', South African Medical Journal 97(8), 755-762.

Meth, C. \& Dias, R., 2004, 'Increases in poverty in South Africa, 1999-2002' Development Southern Africa 21(1), 59-85. https://doi.org/10.1080/ 0376835042000181426

Okonkwo, J.O., 2010, Sanitation, potable water supply and environmental protection benefits, progress and issues for sustainability in developing countries. AISA policy brief, Africa Institute of South Africa, Pretoria, South Africa.

Samie, A., Makonto, T.E., Odiyo, J., Ouaboi-Egbenni, P.O., Mojapelo, P. \& Bessong, P.O., 2011, 'Microbial quality, diversity and anti-biotic susceptibility profiles of bacterial isolates from borehole water used by schools in greater Giyani municipality, Mopani district, South Africa', African Journal of Microbiology Research 5(3), 198-210. https://doi.org/10.5897/AJMR10.338

Statistics South Africa (Stats SA), 2011, GHS Series volume III food security and agriculture $2002-2010$ in-depth analysis of the General Household Survey data, vol. III, viewed 25 May 2015, from www.statssa.gov.za. [].

Statistics South Africa (Stats SA), 2014, General Household Survey 2014. Statistical release. http://www.statssa.gov.za/publications/P0318/P03182014.pdf . [2015, July 01].

Sullivan, C., 2002, 'Calculating a water poverty index', World Development 30(7), 1195-1210. https://doi.org/10.1016/S0305-750X(02)00035-9

Tissington, K., 2011, Basic sanitation in South Africa: A guide to legislation, policy and practice, SERI resource guide, Socio Economic Research Institute, Pretoria, South practice,
Africa.

UNDP, 2011, Millenium development goals. Country report, South Africa, Statistics South Africa, Pretoria, South Africa.

World Bank, 2011, Water supply and sanitation in South Africa, viewed 25 June 2015, from https://wsp.org/sites/wsp.org/files/publications/CSO-SouthAfrica.pdf

World Health Organization; UN-Water, 2014, WHO / Investing in water and sanitation: Increasing access, reducing inequalities, GLAAS 2014 Report, vol. 1, viewed 17 July 2015, from http://www.who.int/water_sanitation_health/publications/glaas report_2014/en/ 